\title{
Los indios civilizados
}

\section{NOTA INTRODUCTORIA}

El documento que Se transcribe a continuación fue presentado por al arqueólogo Pedro Porras en el IX Congreso Internacional de las Ciencias Antropológicas y Etnológicas de 1973 realizado en Chicago. Este manuscrito fue encontrado por Porras en el Archivo de la Congregación Josefina en Roma, sin AUTOR Y SIN DATOS SOBRE SU ORIGEN. ES UN TEXTO DE 71 PÁGINAS CON EL TítUlo LOS INDIOS CIVILIZADOS ESCRITO

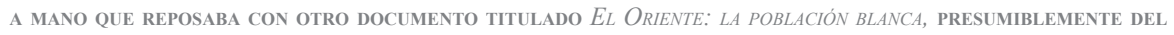
MISMO AUTOR.

Porras EN SU ESTUdio INTROdUCtORIO CREE QUe FUe ESCRITO POR UN CAUCHERO QUE VIVIÓ ENTRE 1890 y 1920 EN EL ORIENTE ECUATORIANO Y DE ACUERDO A SUS CONOCIMIENTOS DE LA REGIÓN SUGIERE EN PROBABLEMENTE SU AUTOR fue un cauchero llamado Manuel Alomía Llory que tuvo su hacienda factoría en la desembocadura del rio Villano en el Curaray; y que para su actividad cauchera reclutó mano de obra indígena de los pueblos de Archidona, Puerto Napo, Tena, Ahuano, San Javier de Pucaurco y Santa Rosa.

EL AUTOR TUVO UNA MUY BUENA CAPACIDAD DE OBSERVACIÓN Y EL MANUSCRITO CONTIENE INTERESANTE INFORMACIÓN

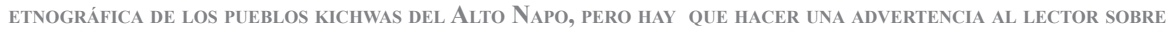

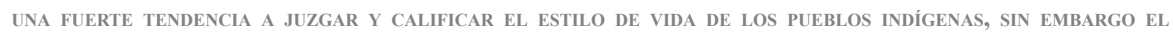
documento aporta Valiosa observaciones sobre la familia, el parentesco, la alimentación, el mundo MÁGICO RELIGIOSO DE LOS KISWUAS ORIENTALES.

LOS EDITORES. 
ntes de ocuparme de la descripción de los pueblos, describiré el carácter general
de la raza indígena que los forma y algunas de sus más prominentes costumbres.
La raza de los indios de Archidona es la misma que la de los pueblos del Tena, Napo, Pucaurcu, Aguano y Santa Rosa, diferenciándose sólo en el dialecto, que cada pueblo lo tiene distinto; son hombres altos, por lo general, esbeltos, musculados, de regular fuerza y -mucha resistencia para caminar a pie: son, para no alargarme, los que en Quito se conocen con el nombre de Yumbos o Quijos.

Carácter.- el carácter de esos indios no es totalmente salvaje; son astutos, aduladores y picaros. Hay también entre ellos algunos audaces y abusivos, pues muchas veces se ha visto cogerle a un blanco -en un camino y descamisarlo de fuerza o de grado.

Alimentación.- el indio, en los pueblos de Archidona y Tena, sobre todo, en donde es escasísima la pesca se alimenta de vegetales: plátano, yuca, papas, boniato y cogollos de palmeras; carne, muy rara vez, y no porque no le guste, sino porque la cacería, (única mantención del indio,) es sumamente escasa y como jamás aumentan en cantidad suficiente, gallinas ni otros animales por su obstinada pereza, viven siempre deseando carne que se la procuran de las culebras, ranas, insectos y gusanos de varias clases; pero lo más esencial en la mantención del indio es la "chicha"........ la chicha oriental, comida y bebida de gente sucia.

Es preciso saber que la "chicha" del Oriente ni con mucho es como aquella agua de jora amarilla de que tan mal habla Montalvo. La chicha de aquí la hacen de yuca ó frutos de chonta cocidos, reducen a polvo en una batea grande y se rodean de ella todas las mujeres allí presentes, con el objeto de masticarla. Llevan la mano de yuca o chonta pulverizadas, ponen en la boca, mastican hasta que se haga una masa endeble y cuando ya está en estado casi líquido arrojan en la bates, y así van haciendo hasta concluir con toda la masa, y así es hecha también la chicha que los yumbos llevan a vender en Quito con el nombre de chantararo. Puede en resumen componerse la chicha de 30 partes de saliva 65 de yuca ó chonta y 5 de inmundicias de -todas las bocas que mastican, las que muchas veces pasan de $20 \ldots .$. y, ¿será posible que haya quien tome esa sucia mixtura? - Pues sí, y hay hombres blancos, civilizados cuya bebida refrescante es la chicha de los indios que compran con codicia; y con mis oídos he -oído a hombres de buena presencia y al parecer civilizados que prefieren un vaso de esa bebida inmunda, antes que uno de cerveza!... (Hay gustos que merecen palos.) En eso nos prueban los aficionados a la chicha que en vez de civilizar a los indios con su compañía se salvajizan aprendiendo sus costumbres.

Mobiliario.- los indios no poseen en sus casas más alhajas que una cerbatana, un hacha, un machete: esas son sus armas y herramientas. En sus ranchos o casas tienen además 6 ó 7 ollas enormes de barro, llenas de chicha y una cama de tablas guadúa.

Vestimenta.- el vestuario de los varones consiste en un pantaloncito de unos $25 \mathrm{~cm}$. de largo, ("cura-balón") que les deja completamente desnudas las piernas y una vara de lienzo con un agujero en la mitad ("cushma"), lo que, poniéndose como poncho les cubre el pecho y la espalda. Las mujeres tienen como único vestuario las 5 varas de lienzo cosido a manera de sábana ("pacha"), en la -cual se envuelven desde el pecho hasta las rodillas, cogiendo los extremos con agujas gruesas o con trocitos de chonta aguzados; y si a esto se añade una faja con la cual se ciñen el talle, quedará completo el vestuario de las hembras.

Este vestuario es, por cierto, el de la mayoría de los indios, hembras y varones, y no se puede negar que entre ellos hay algunos que poseen escopetas, usan pantalones largos y se ponen camisas; pero entre las mujeres es muy pequeña la variación, porque, a las 5 varas de lienzo 
azul les reemplaza una argolla de lienzo de dos varas de circunferencia que se ciñen a la cintura con la faja y un séquito o chaqueta que les cubre el pecho, la espalda y los brazos. Este ajuar femenino usan cuando la fortuna o la civilización les ha obligado a dejar la "pacha" que la usan no obstante en sus viviendas, como vestuario, durante el día y por la noche como frazada. Indios, hembras y varones, cargan invariablemente en sus pescuezos mas o menos cantidades de mullos o chaquiras de colores, en lo que fincan su orgullo, y he visto yo una india, en el Aguano, cargada de chaquiras que apenas podía moverse: pesé por curiosidad y tenía 30 libras!

Vicios.- entre los vicios que adolesce la raza de que me ocupo, los principales son: la pereza, la embriaguez y el robo. Lo poco que ganan en sus viajes, trabajo de pita o cautehue, lo invierten casi íntegro en aguardiente y cuando no tienen dinero para comprar lo -extraen ellos mismo en ollas de barro, del plátano maduro. Por otra parte, esas ollas descomunales que siempre están rebosando de aquella bebida tan fermentada como sucia, hace que esos desgraciados tengan siempre la embriaguez en el cuerpo.

El indio no cultiva más sembríos que el plátano yla yuca: el primero para el aguardiente y la segunda para la chicha.

Siembran también arroz, maíz, fréjoles, caña de azúcar y otros vegetales, pero en tan pequeña proporción que no merecen mencionarse.

La pereza domina al indio absolutamente. Nunca se presta voluntariamente a ganar un real, salvo el caso de que esté embriagado y no -tenga con que completar la borrachera. No faltará quien -se pregunte, ¿cómo los blancos moradores de los pueblos se procuran los servicios de los indios? y lo respuesta es muy sencilla: El indio sirve al blanco, porque se cree obligado a ello. La ignorancia del indio no permite que malicie siquiera en la libertad individual, y por tanto, se creen todos esclavos de nuestra raza; pero aun así, para facilitar peones a un viajero, tiene que intervenir la autoridad y obligar a los indios con amenazas y hasta casi castigos. Lo que hace por los blancos moradores de esos pueblos se procuran todo por medio del -aguardiente, y como ese nunca se agota, paro ¿qué va a agotar si en Archidona sobre todo hay mas alambiques que habitantes blancos?.. Sin embargo, el día en que el indio sepa a ciencia cierta que es -libre, dejará de servir a los blancos, los que se verán precisados a trabajar personalmente o abandonar sus viviendas.

Enfermedades.- la mayor parte de los indios orientales adolescen -de una enfermedad que ellos llaman "siso" y los blancos "carate". Esta enfermedad, dimana de la sangre y es sumamente contagiosa. -Consiste en cubrirse la piel del cuerpo con unas manchas rojas, negras o blancas las que producen comezón, picor y exalan un olor -insoportable, siendo un mal para el que la farmacopea indígena, ni la medicina quizás no ha halla lo remedio.

Este mal se propaga expontáneamente, por el desaseo, es hereditario, se propaga por el contagio y también intencionalmente, pues las indias conocen un medio de inocular el gérmen y hacer desarrollar la enfermedad en pocos días, consistente en dar de tomar caracol molido, polvo de piedra de afilar y los microbios y costras que caen -raspando la epidermis de un enfermo. Esta enfermedad es sin duda alguna la lepra.

Egoísmo.- el carácter de los indios es egoísta hasta lo extremo. -Si un indio hace algo en bien propio y ve que ese algo puede ser -útil a un segundo, lo destruye aunque tenga nuevo trabajo en otra ocasión. Muchos veces se ha visto que uno o mas indios encuentran en su camino un río crecido y se han visto precisados a poner un puente, pero tan luego como han pasado lo han destruido. 
Creencia.- profesan la religión católica, creencias inculcadas por los misioneros jesuitas, pero desarrolladas de una manera tan imperfecta en la obscura imaginación del indio que no sólo es una serie de absurdos, sino interpretada como mas conviene a cada uno, sirviéndoles hasta de disculpa de los mas infames hechos. Y esa religión, la profesan solo en apariencia, sin observar jamás ni el mas mínimo precepto, tal vez porque la limitada imaginación del indio vive -llena con la brujería, la metempsicosis y otras pequeñas creencias que he podido observar encontrando en ellas grandes semejanzas con las de los záparos y las de las tribus salvajes, lo que no me ha -dejado la menor duda en cuanto a que procedan de un mismo origen.

Los indios entierran a sus muertos porque a ello les han acostumbrado los misioneros; pero después de sepultados ponen sobre los sepulcros chicha, comidas, plátanos maduros y más, en trastos de barro. En el solitario lugar que sirve de cementerio, (que es peor lo regular la iglesia,) andan animales de distintos especies, sobre todo de -noche, entre los que abundan mas los conejos y ratas, quienes consumen por entero las provisiones puestas al muerto lo cual visto -por los indios creen de buena fe que el muerto ha comido y bebido todo. Ese cuidado dura un año, "hasta que el muerto tenga chacra en el otro mundo".

La afinidad de creencias entre los indios y los záparos, vincula estrechamente a unos y a otros, pues he podido observar las mismas abusiones, les mismas creencias, con poquísimas variaciones. Creen los indios que los brujos después de muertos se transforman en un tigre que anda haciendo cuanto daño puede. Para esta transformación es preciso tomar en vida mismo el cocimiento de una hierba llamada "puma-yuyu" (cogollo o hierba del tigre), cuyas hojas tienen la forma de las orejas del tigre. El que tal ha hecho en vida, en cuanto es sepultado muerto, puede verse desde el primer día, en el centro de su sepultura, un diminuto tigre, del tamaño de una -pulga que va creciendo con rapidez hasta convertirse en el terrible felino, rey de la selva. Si a ese tigre se lo mata, se lo quema, se arroje al agua las cenizas o se las hace desaparecer en el viento, saldrá de nuevo y crecerá, de entre las cenizas, del seno de las aguas o de cualquier lugar en que el viento haya depositado -el mas mínimo fragmento, porque es indestructible.

Supongo yo que ésta es una creencia deribada de la metempsicosis, alterada con varias invenciones de los ancianos, para que sus parientes no le abandonen, como acostumbran cuando están en -la senectud por temor de que se venguen después de muertos cuando ya se hallen transformados en tigres. Pero nada de esto les vale, pues cuando un indio esté inutilizado por la vejez o por alguna -enfermedad, es mirado con odio por sus parientes, es abandonado completamente hasta por sus hijos que no pocas veces le apostrofan diciéndole, "muerete pronto viejo inútil. Que para nada sirves!"

De esta suerte, la muerte que, para los de nuestra especie tiene algún consuelo cuando el moribundo tiene familia y deudos, para -los indios debiera ser un fin amargo horroroso, porque mueren -odiados, despreciados, hasta por sus hijos, sin quien les prodigue un solo cuidado y los más mueren atormentados por el hambre o por la sed sin tener quien les dé alimento ni de beber!...... pero he visto morir al indio y muere tranquilo; quizás es insensible a las afecciones morales; talvez solo vive su ser material.

En el Aguano, (y de estos casos pudiera citar muchos otros,) se presentó un enorme tigre que se cebó a comerse los perros de los indios y animales domésticos. Se llevaba los perros a la vista de los dueños, quienes en vez de matarlo le dirigían insultos y -gritos diciéndole que no faltaban animales en la montaña con los cuales podía mantenerse y no perjudicar a la gente. Un blanco, - morador de ese pueblo, se puso en acecho y lo mató de un balazo. Resulté ser un hermoso leopardo hembra. Cuando los indios supieron se reunieron todos y fueron a ver el cadáver de la fiera. El bravo cazador esperó oír alguna palabra de gratitud, o siquiera que expresaran su contento por haberlos librado de la temible fiera, pero después de reconocerlo y palparlo le dijeron fríamente: -"No has muerto al tigre, porque no es propio tigre y resucitara aunque lo quemes. 
Esta es la Casita Dagua,- india que había muerto hacía un año,-que tomó puma yuyu... aquí están hasta las manillas"; -y, enseñaban unas listas negras que rodeaban las muñecas del leopardo!....

Entre sus muchas y absurdas creencias, citaré sólo algunas. Todo indio cree que el arco iris es "amarón" (boa), a quien el rayo mata para comérselo. Creen que el rayo es un hombre formidable armado de una escopeta y cuyo poder está limitado por la estrella vespertina("cuillor" $)$ hermana menor de la matutina, (“ducero"), quien en cierta ocasión, por haber el rayo muerto a una familia de indios lo mató con una piedra arrojada por una honda y lo hizo rodar por un barranco, en un lugar cercano a Archidona; pero como el rayo era inmortal, dejó el antiguo cuerpo y hoy es el alma la que anda disparando tiros. En ese barranco existe en efecto un derrumbo de greda amarillenta que tiene algún parecido a los huesos viejos y los fragmentos derrumbados de esa pena son recogidos por -los indios y vendidos a buen precio entre ellos con el nombre de "rayo-rumi" o "rayo-tullu", (piedras del rayo o huesos del rayo), cuyo polvo raspado y tomado mezclado con tabaco es una panacea para toda clase de enfermedades.

La leyenda de la Luna.- le luna, (quilla) es para ellos un ser sobrenatural que tiene su historia, quizás la única tradicción -que conservan y que me permitiré relatarla tal como la he oído. Había una india huérfana, soltera, hermosísima que vivía en una casa muy grande, entre muchos indios más y acompañada por su único hermano. Sin esperanzas de casarse, pasaba la vida triste, dedicada a sus ocupaciones durante los días y durmiendo sola en su "cahuito", (tarima), las noches. Cierta noche vino a su cama un indio varón y le dijo tales cosas que logró impresionarle profundamente, despertando en su corazón un ciego amor por el desconocido, que le -hizo al fin ceder a la pasión. El nocturno visitante le puso como condición el que nunca le averiguaría su origen ni quien era, ni que tratara de encontrarle de día. Continuo durante algunos meses esa vida y el nocturno amante no faltaba una sola noche en la cama de su amada, hasta que después de algún tiempo se sintió embarazada. Viendo que iba muy pronto a ser madre sin siquiera conocer ni saber quien era el padre se su hijo, resolvió la india, dominada por la curiosidad, quebrantar la promesa hecha, sin que este lo -maliciara, porque si bien tenía sospechas de que su amante vivía en la misma casa, no sabía quien de entre tantos era. Tomó pues una pepa de "hurítuo", (fruto cuyo sumo tiñe la piel de un negro reluciente que no desaparece sino después de algún tiempo;) ralló el fruto sobre una hoja y la puso en la cama al alcance de su mano. Por toda la noche vino como de costumbre el nocturno visitante y la india, en medio de las caricias, mojo una mano en el zumo de -"huituo" y le paso por la cara...... Al siguiente día madrugó la curiosa india y se pudo a dar de beber chicha de uno en uno a todos mirando minuciosamente la cara de cada uno, para ver cual de ellos tenía las manchas de "huític" y cuál sería su sorpresa al ver manchada la cara de su propio hermano!.... Reflexionó y disimulo lo más que pudo, sin dar a comprender su emoción a nadie. Por la noche volvió a ir el amante a donde la india, quien le recibió con el mismo amor, pero le informa de que había descubierto quién era, y la manera como lo había logrado, haciéndole presente que -su amor continuaría.

El amante hermano se levantó diciendo que después de lo ocurrido no podía continuar allí y que si quería continuar sus amores le siguiera, pero sin demorar un instante. La india se levantó al momento; se envolvió en la " pacha" apresuradamente y buscó la faja para ceñirse la cintura; pero mientras esto hacía vio que su hermano iba tomando una forma luminosa, se iba alzando desde la tierra y ascendiendo por el cielo. Quiso élla, ya ceñido el talle, seguir a su amante, pero !esta había ya tomado la delantera y ella no podía sola levantarse del suelo....i

Se puso a llorar amargamente mientras el incestuoso hermano ascendía por el espacio indiferente a todo convertido en la luna. La -india dio a luz y luego se transformo en "geloco", gavilán nocturno que en las noches de luna canta melancólicamente desde que sale del horizonte, y el hijo, más chico se transformo en ruiseñor, ("tuayo”), que también canta con melancolía en 
Cuando no son ellas las enfermas, son los hijos tiernos, a quienes hacen curar aún sin estar enfermos, para crearse un pretexto de relaciones con el brujo, porque éste, a mas del pago que exige en ropa dinero o lo que el tiene a bien, "se cobra" en la mujer, hija, hermana o pariente del enfermo o en la misma enferma si es mujer, lo cual es aceptado como la cosa más natural del mundo, pues le es lícito al brujo exigir esos "pagos", extra, fuera del teatro de las borracheras. Mi observación me ha hecho deducir de todo lo que he visto que las mujeres y los brujos son los únicos que no creen absoluctamente en la brujería pero conservan el prestigio de la "ciencia", por conveniencia personal; las primeras por la corrupción y los últimos por conservar su protestad absolucta. Y hay mujeres -que materialmente sacrifican a sus maridos desgraciados, obligándoles, por ese sistema, a que cedan voluntariamente todas las ganancias que obtienen por medio del trabajo al brujo, con quién viven públicamente bajo la apariencia de estar pagando curaciones y sujetando al creyente marido como esclavo de los dos.

En mis peones ha observado minuciosamente esto y también en los pueblos, pero me ha sido imposible el remediarlo porque al indio (en general) pueden decirle que no hay Dios, que él no existe, que el sol no alumbra a que el día es noche y tal vez creerá, pero si le dicen que la brujería es una farsa, es incomoda y no da crédito, aunque le prueben con hechos palpables, pues la fe en esa burda patraña ha sido mamada en la leche de las madres, inculcadas por los padres, transmitida por antiguas tradiciones e impuesta por la sugestión de los brujos y hasta tal extremo está aferrada en la conciencia del indio que creo se dejaría quemar vivo antes que abandonar sus creencias.

No hay duda que el ánimo del enfermo puede ser causa de una curación cierta en varias enfermedades no muy graves; y la fe, infunde, ánimo; de esta manera, algunos de los que pasan por ese sistema de curación a la que sin escrúpulo llamará magnética, se curan, pero no por las prácticas del brujo sino por la exitación de la decaída esperanza por medio de la fe ciega de los sujetos, o más claros por la terapéutica sugestiva; y estos, contribuyen de buena fe a dar prestigio al brujo. Algunos enfermos mueren; pero cuando tal sucede, el brujo dice enojado al ver que no le pagan bien, el mismo lo mató.

No solo los brujos tienen la potestad de hacer llover y hacer cesar la lluvia sino que ese privilegio ha sido generosamente cedido por los brujos a cualquier indio.

Tienen todos los indios en sus chacras una planta parecida a la - "yerba luisa” diferenciándose sólo en que las hojas son tubulares como las de la cebolla y de color más obscuro. A esta planta le llaman "dondoma” y sirve para hacer llover para la cual tienen dos -fórmulas.

Machacan las hojas de "dondoma" hasta reducirlas a estopa; se desnuda un indio entra al agua, zambulle y sacando la boca llena de agua sopla verticalmente hacia el cielo. Moja el dondoma machacado y asperjea en el aire el zumo en todas direcciones, de manera que caiga como menuda lluvia. Esta operación la repiten por cuatro o -cinco veces concluidas las cuales arrojan, (siempre para arriba), las estopas del dondoma. Cuando quieren que la lluvia sea con viento pronto, dan furiosos soplidos y si quieren que hayan rayos, mezclan en el dondoma una pequeña porción de "rayo-rumi".

La otra fórmula consiste en tomar una concha de tortuga de cualquier tamaño o especie, moler ají y poner en ella Quemar la concha con el ají en el fuego y arrojarla caliente al agua. Entra enseguida el indio desnudo al agua hacer lo mismo que con el dondoma, que agregando a esta segunda fórmula produce efectos inmediatos y violentos, formándose al momento una terrible tempestad. Nunca llueve sin causa para el indio: siempre es que alguno hace llover, y cuando no tienen a quien culpar, hasta los "saginos", que andan en grandes manadas tienen potestad de hacer llover, así como las lanchas a vapor..! Es tal la fe que tienen en esas supersticiones que $a$ ninguno le falta lo necesario para hacer llover cuando quieren que crezca un río o hacer mojar a algún viajero y cuando falla el "paje”, (así llaman al sistema), dicen que el "dondoma" ha sido 
mal cultivado, o que el ají no era maduro y, como días después, llega alguno en que llueve, dicen al fin que se ha atrasado la lluvia hecha por ellos!... El hacer cesar la lluvia es más fácil. Basta levantar la cara al cielo y soplan repetidas veces en distintas direcciones y si soplan con humo de tabaco, creen que el efecto será más rápido. En las lluvias se ve siempre soplar a los indios. El aguacero no pasa; pero el indio sigue soplando. Al fin, después de algún tiempo cesa de llover y el indio lo atribuye con orgullo a la eficacia de sus soplados esas cosas dan fama a los indios y les aferran en sus brutales supersticiones.

El "ságrag", (brujo) es el dueño absoluto de lo ajeno, es un dios en el pueblo, tiene la potestad de hacer llover y hacer cesar el aguacero cuando quiere; mata a sus enemigos a cualquiera distancia que se hallen, y todo el que muere es porque le ha dado un motivo de disgusto. Toda enfermedad es atribuida a la brujería: si es desintería, es porque el paciente tiene clavados en los intestinos trocitos de chonta; si son neuralgias, en la parte dolorida tiene muchas chontas; y hasta los dolores del parto son atribuidos a la brujería, pues no hay india que antes del momento crítico no se haga sacar unas cuantas chontas o birotes que a juicio de ellas pueden impedir la libre salida del niño y morir la madre. Esta religiosa creencia es causa de una mortalidad desproporcionada en los pueblos, porque las enfermedades nunca son combatidas con más medios que con la brujería y los enfermos y familias de ellos creen en su seguridad fanática que "lo que no ha podido el ságrag ni Dios podrá remediarlo”, y mueren convencidos de que han hecho lo posible por salvar la vida. Fiebres intermitentes disenterías y otras enfermedades mas fáciles de curar con medicinas sencillas y conocidas, han asolado los pueblos en todo tiempo porque es innegable que si bien la terapéutica sujestiva puede ser eficas para algunas enfermedades, para algunas dolencias agudas por la influencia directa del masaje -y hasta por la potente imposición de la voluntad, para otras es totalmente inútil ya que para curarlos es preciso combatirlas con medios mecánicos que obren de manera conocida en la economía, descargando el estomago, eliminando parásitos restableciendo la digestión o la circulasión, estimulando o atenuando las funciones de algunos órganos y así según las enfermedades.

Entre las repetidas veces que la viruela ha asolado los pueblos del "Alto Napo", sitaré la última el año 1896. Los indios se vieron atacados del terrible "muruy", (viruela) y se atuvieron' a la brujería con lo que se propagó la peste sin demora. Los indios contagiados ya de la enfermedad huían de sus pueblos y de sus viviendas, regando el mal por donde pasaban. Familias numerosas emigraban con el contagio ya a ocultarse de la enfermedad e iban dejando marcados los derroteros con muchos enfermos y moribundos que después de crueles agonias quedaban insepultos....... Hubo familia compuesta de 28 individuos de la que solo escapó uno, (el padre,) que era vacunado........ Los indios que habían sido vacunados o habían visto vacunar, creyendo que el fluido de la vacuna era extraído de las pústulas de la viruela, inoculaban intencionalmente el mal en los sanos propagándolo en grande instantáneamente. Los pueblos quedaron abandonados!......... cuando se reorganizaran, el $65 \%$ de la población total, incluso los brujos había perecido!......

Como los honorarios que ganan los brujos en curaciones son -exorbitantes y continuos, no necesitan trabajar para vestirse; tienen ropa y plata sobrada para sus necesidades; herramientas y armas de las mejores calidades, no hacen chacras porque con las ajenas -les sobra; la primera presa que caza un indio es para el brujo, por que si no le dan les dañaría la escopeta, el perro o la cerbatana con que han cogido, y de esa manera, viven esos infames nadando en grandeza a costa ajena.

Me ha sucedido muchas veces encontrar indios gravemente enfermos con algún mal. Llevado de mi corazón compasivo les he curado, con remedios que nunca me faltan. Sanos ya de sus enfermedades he escuchado sus conversaciones y la curación nunca la atribuyen al -remedio del odiado "blanco", sino al "ságrag"...... 
He notado que aunque vean y están convencidos de la eficacia de -los remedios del blanco, tienen marcada repugnancia que uno de nosotros tuviera para confesar que se ha curado de una enfermedad por medio de la brujería del indio.

Los brujos venden la brujería y la enseñan a cualquiera que les paga bien. Seguramente, durante el mes que dura el estudio el -profesor enseña al discípulo todas las trampas que componen esa -burda farsa en la que por desgracia tiene el papel mas importante la más poderosa fuerza de la naturaleza cual es el magnetismo animal tan burda e infamemente explotado....

Prostitución e Infanticidio.- aparte de la prostitución descarada en las escandalosas escenas de hetairismo, tienen las indias otros pretextos para la prostitución, uno de los cuales es el “ Supai", (demonio). Cuando una india soltera se empreña, el fruto no es -hijo de nadie, sino del "Supai"..... Había en el "Aguano" un indio conocido con el apodo de "Mucu", el cual tenía una hija que resultó preñada. Como el padre le preguntara quien era el padre de la criatura que debía nacer, la india dijo que el "supai" le había cogido sola en la montaña y que debía ser hijo del el que tenía en sus entrañas......... Llegó el día del parto, y en cuanto nació la criatura encendieron una cantidad de leña de chonta, que "Mucu" tenía preparada para el caso, introdujeron al niño en una olla de barro nueva la cual pusieron en media hoguera, quemándole vivo a la inocente criatura, mientras la madre desnaturalizada contemplaba con cierta satisfacción el acto bárbaro, por llevar a feliz término su mentira.

EI Sr. Dn. Antonio Llori, que es quien me ha referido ésto, tenía su posesión en el "Aguano"; le dieron noticia de lo que ocurría y corrió al lugar del crimen por ver si salvaba a la criatura, pero cuando llegó se encontró con un poco de cenizas dentro de la olla enrojecida por el fuego de la hoguera ya casi consumida.

La corrupción y el crimen se dan la mano en esa raza degradada. -Son corrompidos desde antes de ser aptos para la corrupción, y entre las hembras, creo yo que a excepción de las estériles no habría una sola que no sea autora de uno o mas infanticidios.

A menudo ocurre que resulta embarazada una mujer que no tiene marido. Llegó el día de dar a luz y en el mismo momento matan a la -criatura ahogada o rota la columna vertebral. En el poco tiempo que residí yo en el "Aguano", ascendieron a 25 los infanticidios -que llegaron a mis noticias siendo autoras de todos las mismas desnaturalizadas madres, y sépase que ese pueblo solo se componía de 50 familias.

Alcoholismo y Libertinaje.- la corrupción en la raza india pasa de los límites de lo imaginable, aprovechando, sin pérdida de ocasión todas las casi cuotidianas borracheras para entregarse al más desvergonzado y escandaloso hetairismo. Esas bacanales (que, entre los caucheros han logrado reglamentarse), entre los indios de los pueblos ocupan todos los días de la semana (exceptuando solo el en que salen al pueblo, que son repartidos entre las familias que componen un partido cada una de las cuales tiene la obligación de hacer la chicha para el día señalado y llamar a todos los vecinos del lugar, los que concurren sin quedar ni los niños de pecho, pintados las caras con achiote, añil y otras porquerías. Instalados en la casa de la borrachera, las indias dueñas de la chicha principian a repartir el sucio licor en grandes cazuelas de barro, " pilches" o tazones. Después de beber dos o tres veces cada uno la chicha que van amasando las indias con las manos hundidas hasta las -sucillas manillas en los trastos, se ponen en pie todos los indios varones que tienen tambores (“cajas") y "pingullos", (pitos); piden permiso en alta voz a todos los concurrentes y principian a golpear los tambores, todos a un tiempo con un compás idéntico de 1 x 3 que se oye en nuestros teatros durante los entreactos; se ponen en hilera uno detrás de otro y forman un círculo completo uniéndose la cabeza con la cola, el que principia a girar sin interrupción sobre su centro hasta que termina la borrachera, en medio de un ruido infernal. A esto llaman "cajear", y en esa operación van relevándose unos a otros interminablemente. La cajeada es como si dijéramos el período de preparación o conquista. Las mujeres sentadas a todo 
el contorno de la casa no apartan un momento la vista de los que dan -la vuelta, y estos a su vez dirigen sus miradas a las mujeres y con mas tenacidad a las que pretenden: no tienen necesidad de hablar, pues las miradas y las señas lo hacen todo. Pronto se desprende del remolino viviente un indio; da su tambor a otro que se intercala en su lugar y sale de la casa tomando hacia el fondo de un yucal o platanar. Inmediatamente y sin el menor disimulo le sigue la mujer comprometida tomando el mismo camino a vista y presencia del marido, padre o pariente, (que todos saben bien a que va) y.......... lo demás no hay para que decirlo. Algunos minutos después regresa esa pareja y sale otra, y así sucesivamente. Hay ocasiones en que salen cuatro o más a un mismo tiempo y toman distintas direcciones, siguiendo las mujeres ajenas o solteras en igual número. Algunos maridos borrachos ya, se sienten celosos después de haber visto a sus mujeres con otros, pero el "randi", (desquite) pone fin a su disgusto, desquitándose con la mujer de su rival o estropeando a la suya. No hay borrachera en que no sean fuertemente estropeadas las mujeres y sin embargo son las primeras que inventan las borracheras haciendo la sucia chicha.

El ruido infernal de los tambores en el que, cual si en un mar tempestuoso se perdiera y volviera a asomar una frágil barquilla, hiere los oidos y se pierde el destemplado y agudo silbido de los pingullos, tiene un poder admirable para despertar las sensaciones en las indias.

Yo las he visto ir tomando asiento, silenciosas, mojigatas y solapadas con la mirada fija en el suelo cuando principia la borrachera; oir los tambores y levantar las cabezas en todo tino; y al ver el remolino humano que al compás del tambor principia a girar con paso mesurado y lento, avivárseles los ojos hasta despedir miradas centelleantes; hinchárseles las ternillas de la nariz como si no fueran suficientes para dar salida a todo el aire contenido en los pulmones; los labios húmedos y entreabiertos, ponerse a provocar con -ademanes, señas y actos deshonestos, descubriéndose al fin con más o menos disimulo, partes del cuerpo que toda mujer considera como sagradas!.......... y, ebrias ya, de verdad o en apariencia, concluir, primero en risas sonoras y provocativas y luego con gritos agudos y destemplados de histerismo por echarse a la espalda el primer indio que ha caido borracho o llevarlo a rastras monte adentro!...

$\mathrm{He}$ visto, lector, todo eso y por eso lo relato. He asistido a esas escenas execrables por estudiar las costumbres más intimas de los indios y he observado actos más deshonestos, más desvergonzados que callo por no ofender el pudor.

Me he convencido por mis observaciones que la borrachera no gusta al indio sólo por la embriaguez, sino aún más por el hetairismo y la corrupción sin freno, por el cambio de mujeres, por la libertad de apropiarse de cualquiera. Y se hartan de chicha, hasta que, como ellos dicen "se llena el estómago hasta la raíz de la lengua" y -cuando ya no cabe ni una gota más, salen de la casa y devuelven por la boca todo lo que han bebido, después de lo cual vuelven a entrar y vuelven a beber veneno, para volver a salir a la misma operación. Puede, en una palabra, compararse al indio en una borrachera con un aparato de destilación que se carga; absorbe el alcohol que puede mientras está la chicha en el estómago y luego arroja el mosto por donde mismo ha entrado, colectando el alcohol de cada parada en el cerebro, hasta quedar completamente inutilizado......... y como -la chicha de yuca tiene apenas de un 7 a $12 \%$ de alcohol del cual calculo que solo la mitad es absorbido por la economía animal, para -emborracharse un indio necesita lo menos diez paradas y diez descargadas del alambique. De esta manera, lector, la borrachera de los indios orientales es el acto mas sucio que se puede imaginar, no sólo por los escándalos horriblemente inmorales sino también -por el sistema de emborrachamiento que deja todo el contorno de -la casa cubierto materialmente de desperdicios repugnantes y nauseabundos.

Cuando ya la embriaguez se ha generalizado desaparece en absoluto el pudor que se ha notado al principio y ya no son las salidas ocasionales y continuas las que ponen en contacto a los hetairistas sino que todo se torna en un desorden horroroso, indescriptible del cual hastiados ya y concluida la chicha terminan por irse a sus casas, para a la siguiente noche asistir a la misma bacanal en -otro lugar. 
Para estos actos no se recelan de nada ni de nadie. Los muchachos de tiernas edades la presencian todo y en sus juegos infantiles procuran imitar lo que han visto en sus padres, parientes y mayores, y de allí viene el que el indio, hembra o varón sea generalmente corrompido de cuerpo y alma desde una edad que, en nuestra raza parecería imposible. Yo, mas de una vez he encontrado chicos de menos de cinco años en prácticas deshonestas; he comunicado a los padres, indicándoles que los corrigan, y éstos en vez de reprender a los niños se han reído con criminal satisfacción, como nosotros riéramos al oír que un hijo nuestro de esa edad sabe ya leer y escribir. Si un muchacho llevado de un raro instinto de repulsión no es corrompido a los 6 ó 7 años, le corrompen intencionalmente sus padres o sus mayores, con prácticas que solo al pensarlas se resiente el pudor.

Al principio creí yo que "esos desórdenes" eran ocasionados por la embriaguez; pero pronto me desengañe de ello observando que el indio por lo general no necesita estar embriagado para entregarse al hetairismo, sino que la borrachera es solo un pretexto de reunión convencional conocido, pues por pequeña que sea la cantidad de chicha que hay, los indios fingen y hacen gala de estar borrachos para entregarse a la crápula con libertad........ ¿qué digo con

Libertad con escándalo?.

Para conocer estos instintos y costumbres se necesita de grande observación, pues como he dicho, después de algunos años de residir en el Oriente y de creer que conocía el carácter del indio y sus costumbres y hasta de tener algo escrito sobre el particular, principie a conocerlos cuando tuve bajo mi mando a un grupo de peones sacados de los pueblos, con los que fundé mi primera posesión "Las Mascota" en la desembocadura del río "Villano". Los indios me dijeron como primera cosa que querían llevar una vida semejante en todo a la que llevaban en el pueblo, para no extrañar a sus parientes y les concedí plena libertad para ello. Cuando ya tuvieron chacras de yuca principie a observar los desórdenes y el escandaloso hetairismo. Los indios se habían repartido los 7 días de la semana tocando a dos matrimonios cada día en el cual tenían la obligación de hacer la chicha para la borrachera. De esa manera no tenían un solo día de la semana libre para el trabajo. Convencido por mi propia observación de los horrorosos actos que se consumaban en esas bacanales quise obligarles a los indios a llevar una vida mejor, exigiéndoles que respeten el vínculo del matrimonio, que las mujeres sean fieles a sus maridos y para conseguirlo me valí del sistema de afear su conducta y explicarles algunas de las ventajas de la monogamia. Las hembras fueron las más chilladas; aula manta pécha (desde los abuelos) tenían esas costumbres y el bulanco, (blanco), el ser mas despreciable no sería quien las rompa............ organizaron una conjuración para asesinarme; de en medio de una borrachera mandaran a mi casa 5 indios arumados, con tal objeto y yo salvé milagrosamente gracias a mi prudencia; (año 1909). Después de esto logré no obstante, por medios mas prudentes y disimulados el reglamentar las borracheras mientras se hallaban en la finca, dejándoles los jueves y domingos para sus excesos y haciendo que los demás días de la semana trabajaran en bien propio.

Tres años después, (1912), creyéndoles ya bastante racionalizados, ataqué nuevamente mi proyecto de reforme y quise moralizar las costumbres de mis peones, obligando a cada mujer a vivir solo con su marido eliminando el adulterio escandaloso; pero las indias organizaron otra conjuración para asesinarme a mí y a mi familia, saquear e incendiar la casa y fugar. Entonces, a costa de casi perder la vida, logré reglamentar más aún las borracheras, consintiéndoles sólo los días domingo; y así, poco a poco, sin fuerza ni violencia y valido de la astucia he llegado a coronar casi mi proyecto hasta que ahora me piden licencia para la borrachera y saben que solo hay pretexto de hacerla cuando el indio tiene motivos para enorgullecerse o alegrarse como un matrimonio, el regreso de un largo viaje o el éxito de una empresa productiva. Les he desterrado de mi vecindad haciéndoles que construyan sus casas a 1.500 mtrs. de distancia de la mía, al otro lado del río, a fin de que no me fastidien con esos malditos tambores a los que, dicho sea de paso, odio con mas horror que una beata puede odiar al demonio; y desde sus viviendas, cuando 
hay motivo justificable vienen a pedirme permiso para la borrachera y yo les consiento, no sin considerar por cierto los brutales actos de hetairismo que llevan a cabo en esas bacanales infames. Y yo comprendo que allá a solas tienen sus bebidas ocultas, suprimiendo el alborotado de los tambores, pero lo tolero porque veo que es materialmente imposible conseguir una modificación más rápida en sus costumbres salvajes, convencido de que en 9 años de vivir bajo la tutela de un patrón bondadoso que les ha inculcado la moral con el ejemplo y la palabra, no se ha conseguido sino reglamentar el vicio o el pretexto, pero no corregir por completo el hetairismo y la prostitución: con mas disimulo sí pero no han renunciado a sus prácticas ni han cambiado en sus instintos, de lo que eran en el pueblo, adquiriendo solo un poco de pudor y disimulo, con respecto a mí, que lo que hace entre ellos se conocen y entienden perfectamente.

Casi todos los caucheros han logrado reglamentar las borracheras y a propósito de esto recuerdo en este momento la ocurrencia de uno para impedir las borracheras escandalosas de los domingos.

Hallábase nuestro sujeto pensativo sobre la manera de imponer la prohibición a los indios, cuando llegó el correo de Quito en ocasión de que tres de sus peones se hallaban presentes. Le entregaron tres cartas que leyó en voz baja. Los peones le preguntaron, con la curiosidad propia del indio, que noticias habían venido en esas "quilcas", (cartas); y él, queriendo aprovechar esa coyuntura a favor de su proyecto y ocurriéndosele una idea luminosísima, les dijo con rostro compungido y muy serio:

La noticia mas grave que pueden imaginar, y no quiero ocultarles, porque ustedes mismo tienen la culpa. Por el uso inmoderado que los indios han hecho desde tiempo inmemorial de los días domingos, gastándolos inconscientemente en las borracheras y desórdenes se han concluido todos y no quedan ya mas que los días ordinarios...... si bien es sensible esta desgracia, por otra parte no deja de ser una ventaja, porque ese día fatal les robaba hasta la salud. Los indios cuentan los días de la semana. Llegó el domingo y fueron a preguntarle al patrón que día era y les dijo seriamente: - "Ayer era sábado y hoy es lunes".

Pudo sostener por tres meses la mentira, tiempo en que pudo reglamentar la borrachera.

Por deshonesta no quiero citar aquí la creencia general que los indios tienen sobre el período de gestación del feto en su vida intrauterina, creencia que las mujeres fomentan con astucia y entusiasmo a fin de justificar sus brutalidades durante la preñez periodo en el que, tal vez violentadas por esa creencia, aceptada de buena fe por algunas, padecen de una exitación rayana en locura, que propasa los límites de la ninfomanía y se entregan con más desenfreno a la prostitución creyendo con ello, ó aparentando creer que favorecen el pronto desarrollo y la robustez de la criatura. Si a un indio le dicen que el hijo que va a parir su mujer no es suyo, le niega rotundamente y dice: "imposible"! aunque sean los pies han de ser míos".

Un cauchero trajo del "Napo" a sus peones y fundó su establecimiento en este río para trabajar en la extracción de cautchuc. Uno de los indios no quiso traer a su mujer y la dejó en el pueblo, en donde la india se entregó a la vida que acostumbran. Al cabo de dos años el indio ocurrió por su mujer quien vino acompañada de la madre; pero al recibirla el marido, vio con disgusto que estaba preñada y se lo dijo a ella y a la madre quien le tapo la boca con las siguientes palabras: - ¿ De quién va "a ser ese hijo sino tuyo?..........quedó tu mujer" preñada cuando la dejaste y es muy natural que el chico haya demorado en crecer "porque la madre no estaba con su marido, "caso en que la formación del niño sólo es "favorecida por la madre"; siendo así pues, el "tiempo que ha pasado sin parir es la mejor" "prueba de la lealtad de tu mujer quien" ahora que se halla contigo no demorará "en dar a luz"; y en efecto, dos meses después parió la india y el marido reconoció como suyo a un hijo que había nacido después de 26 meses de separación.

He observado que el incesto es muy común entre los indios y hasta pudiera asegurar que sus primeros pasos en el camino de la corrupción son dados entre hermanos y parientes que viven en una misma casa. Se han visto muy repetidos casos de incestos de padres con hijos, registrándose 
entre muchos el de un indio de apodo "Osha” con su hija Carmen a quien no lograra corregir ni los blancos ni las autoridades, en el "Aguano". Nunca sin embargo, contraen matrimonio entre parientes, por lejanos que sean.

No es raro tampoco el que cuando indios de un mismo sexo se encuentran solos en número de dos o más, observar tendencias de la repugnante sodomía y otros crímenes contra la naturaleza que me repugna el consignarlos.

El ser "compadre" o ser "amigo" entre indios equivale a tener pacto de concubino declarado aún fuera del teatro de las bacanales.

Las indias hembras tienen aversión a los hombres blancos y supongo yo que esa adversión viene del odio de raza y de las creencias inculcadas por los varones, pues he oído tantas anécdotas, tan falsas y tan sucias de nosotros que me repugna el relatar ninguna. No solo odio, no solo aversión he podido notar en las indias hacia nosotros sino horros por superticiones y cuentos oidos, sistema con que el indio pretende librarse del cruzamiento y conservar su raza pura. El blanco para ellos el ser mas degradado, es "upa", (ignorante), porque no cree en la brujería ni profesa sus creencias y abusiones, porque sus costumbres son opuestas en todo a la de ellos, y hasta tal punto llega ese odio mortal, que, la india que ha tenido relaciones con un blanco o ha servido siquiera en su casa algún tiempo vive excomulgada entre los indios para siempre. El robo, entre los indios es una especie de religión que profesan todos, pero el indio nunca es llamado ladrón por los de su raza, por más robos que haya hecho; esa palabra es solo, apropiada para designar a los blancos. En 16 años que llevo de vivir aquí hasta ahora no he oído que un indio le haya llamado a otro "shugua", (ladrón); y para designar este vicio entre ellos dicen: "llángac", (tocador, porque "llangar" es tocar, palpar) y al que propasa ya de los límites le designan con: "maqui purichic", (que hace andar la mano). Continuamente se ven desaparecer del camino de Quito bultos enteros de mercancías o siquieran se notan fracturas en ellos. Si un indio entra en casa de algún blanco nunca sale con las manos vacías, pues siempre lleva consigo algún hurto que lo hacen con mucha habilidad, burlando la vigilancia del dueño; y no roban por necesidad, sino por costumbre, pues yo mismo, en manos de los indios he visto objetos cuyo uso ignoran.

Pereza.- el indio es deudor desde que tiene uso de razón. El comercio con los indios se reduce a puro crédito el que no es cubierto sino mediante los heroicos esfuerzos de los acreedores. Los moradores blancos del Oriente tienen que hacer muchos sacrificios para cobrar sus deudos, y muchas veces, las más, aquellas son infructuosas y tienen que hacer cancelar a los deudores en trabajo personal. El indio trabaja cuando le obligan, pero tan mal y de tan mala gana que casi vale tanto como si no lo hiciera. Trabaja desde la 7am. Hasta las 11 ó 12 y a esa hora se alzan. Un peón de la costa puede trabajas en un día el tanto que trabaja 10 indios en el mismo espacio de tiempo.

Las mujeres trabajan mas que los varones. En sus viviendas el varón no tiene otra ocupación que hacer "birotes" (saetas para cazar con cerbatana), y andar en la montaña pocas horas. Las mujeres hacen solas los desmontes para sembrar yuca y plátano, siembran, cultivan los sembríos, hacen la chicha, cocinan, rajan leña, y en una palabra proporcionan el sustento diario a sus hijos y maridos ociosos.

Cuando un indio encuentra un arbol de cautchuc hace una excursión de dos semanas, para extraer la preciosa gama y al cabo de ese tiempo sale orgullosísimo con dos o tres libras de cautchuc las que emplea, no en pagar a sus acreedores sino en comprar lo que necesita de donde otro a quien no debe y al que con engaños le saca a crédito lo que puede.

Mata por placer.- la cacería es una de las ocupaciones que se prestan para juzgar al indio en general pues en eso todos son los mismos. El indio no caza solo por la necesidad de llenar el estómago de cadáveres de animales, sino también por el placer de matar. Se complace en matar 
aves y animales cuando tiene de sobre para la mantención y dejarlos abandonados por donde pasa; pero no consiste su placer solo en privar de la vida a seres inofensivos sino que cuando puede coger vivo a un animal se complace en atormentarlo y prolongar su agonía: ese es su mayor deleite. Si logra coger un animal vivo lo mete al fuego y principia su diversión: cada contorsión de agonía, cada esfuerzo que hace por librarse de las llamas le produce una alegría y una satisfacción que se traduce en las sonoras risas, y prolonga la vida de la víctima lo mas posible, haciéndole morir a fuego lento. Aves que cogen de los nidos, aves y animales que cogen en trampas, son arrojados vivos al fuego para dar placer a los espectadores que gozan y ríen indeciblemente con las contorsiones de agonía y los esfuerzos inútiles de las víctimas por salvar de las llamas. La muerte que da a las aves y animales con la cerbatana es la mas piadosa.

Penetra la saeta envenenada, sin que la presa sienta casi; el veneno circula con rapidez medio minuto después cae, completamente muerta, sin proporcionar al indio la satisfacción del martirio.

Por eso quizás será que el indio prefiere la escopeta a la cerbatana, porque con ella coge aves y animales heridos o baldados, en los que puede ensañarse con sus salvajes y bárbara crueldad.

Nunca podré olvidar una escena que presencié con mis peones. Ibamos por la montaña y encontramos una partida de monos, "choros"o "fraguadas" (simia Ursina). Los indios se pusieron a tirar y yo también con mi carabina maté a uno, pues estaban muy gordos y son un excelente bocado. Teníamos ya 4 monos, cada uno del tamaño de un niño de 6 años, es decir, mas de lo suficiente para comer todos, por lo que les ordené que no mataran más. El último tiro fue a una mona hembra con cría que cayó herida en el vientre, cargada de su hijo. Los indios todos se rodearon del desgraciado animal y reían estrepitosamente viendo los inútiles movimientos del simio: le tiraban palos, terrones, le jalaban los intestinos salidos, para desesperarla más. Ciego de ira les grité de donde estaba que no hicieran sufrir a ese animal y cuando ví que no oían o no querían oír, me acerque resueltamente con mi carabina: qué cuadro! Los indios reían con un placer criminal y la pobre mona, con su hijo fuertemente apretado contra el pecho como si se lo fueran a quitar, con la mano que le quedaba libre se limpiaba los ojos cubiertos de lágrimas para dirigirlos a sus verdugos y a su hijo, como implorando misericordia para este............. las lágrimas le corrían por la cara, dándole una expresión que partía el corazón de dolor. Los indios que se preparaban a chamuscarla viva para continuar su diversión y yo no pude resistir más: apunté con mi carabina, disparé y puse fin a la vida de la desgraciada víctima, taladrándole el cráneo de un balazo.... hasta muy tarde de ese día noté el disgusto de los indios por haberles quitado su diversión favorita: al siguiente día lo habían olvidado ya..... han pasado 9 años de lo que relato y el recuerdo vive aún en mi alma.

En cuantos asesinatos se cuentan perpetrados por indios a blancos, las víctimas han sido horriblemente martirizados por los verdugos y salvajes instintos de crueldad.

En donde se abrigan esta clase, (no diré de sentimientos), sino de instintos, en donde está así la razón pervertida ¿qué bondad, qué compasión puede hallarse? Inútil sería pues buscar en el indio oriental esas virtudes propias de la exquisita sensibilidad del alma. Para un ser esencialmente material como el indio oriental no existen las sensaciones morales ni los dolores, tal vez por que su alma ha sido dominada por la mentira, y así no conoce afecciones ni dolores; no ama a sus padres, sino que en cada borrachera los estropea cruelmente; no ama a su mujer, por eso el hetairismo; no ama a sus hijos, por eso los corrompe, y un hombre que no ama a quien vive unido formando la mitad de su hogar, un hombre que no ama a los seres indefensos que necesitan de su protección, y está obligado a quererlos como a carne de su carne siquiera ¿qué amor puede tener por sus semejantes?

En Diciembre de 1908 vinieron del Napo conduciendo el Sr. Secundino Urbina, por el Curaray, varios indígenas de los pueblos del "Tena y Archidona" residentes en el pueblo de "Atahualpa". En el regreso se enfermaron algunos de ellos y uno murió en "San Antonio": 
su cuerpo fue arrojado al agua por sus compañeros y continuaron su viaje de subido por el "Curaray". Mas arriba del Napo murió otro, y el cadáver fue abandonado en una orilla del río sin siquiera sepultarlo. Cuando pasaban por mi posesión "la Mascotta", los mandé llamar, sabiendo su situación para curarles, hacerles que se repongan con alimentos y darles víveres para el viaje, y aquella misma noche continuaron, diciendo a mis peones que ningún remedio podría curarles contra la brujería. Tres de los indios iban no muy graves con tercianas, pero lo suficiente para no poder trabajar en la canoa durante el periodo de la fiebre. Un día arriba de la desembocadura del Nushino fueron abandonados dos de los enfermos en una playa, en donde murieron de hambre sin duda.

Otro de los enfermos fue abandonado en otra playa, cerca de "Yahuate-yacu" y también pereció. Los tres únicos indios inhumanos que se regresaron a su pueblo eran parientes muy cercanos de los que dejaron abandonados en las desiertas playas del "Nushino"........ Pocos días después tuve ocasión de ver los despojos de esos tres infelices, asistiendo al reconocimiento del supuesto crimen del que se les creía autores a los salvajes del "Nushino".

Ingratitud.- a ningún indio se le hable de agradecimiento, porque no sabe lo que será. Si se le regala alguna cosa de ropa, comida o dinero, contesta con un gruñido que parece decir "ari" (Si); pero si se le da un poco de aguardiente o chicha, se oye al momento de sus labios el "Dios pagarachu”, (Dios te pague).

Las conversaciones entre los indios se reducen a noticias; a hablar mal de los blancos, a sucesos de cacería o pesca, a elogiarse cada uno a si mismo, a la brujería y de preferencia a hablar deshonestidades.

Ningún indio se ríe sino cuando oye una palabra sucia, siendo más jocosa las más deshonestas: para esas conversaciones no guardan consecuencia a nadie, ni así mismos, y refieren con los menores detalles los que nosotros pudiéramos considerar como "secretos conyugales".

Con su mujer y sus hijos.- nunca acaricia a su mujer el indio, jamás le dirige una frase cariñosa y siempre sus palabras hacia ella son lacónicas órdenes o severos mandatos. Nunca llama a la mujer por su propio nombre, pues cuando ésta le oye es el "can" (tú); cuando habla de ella es "pai", (ella), o "uyarijuc", (la que suena), u otros paliativos con que se evita de decir, "mi mujer"; o llamarla por su propio nombre.

Cuando después de algún tiempo de estar ausente, llega el indio a encontrarse con sus padres, familia o mujer, ni un abrazo les prodiga, ni una frase cariñosa, ni una palabra, ni una mirada; cuando más deja salir un gruñido ambiguo que se parece tanto a una tos pujida como a una risa forzada, y cuando la mujer le da la chicha, la riega con ira y desprecio.

Al indio no le seduce la hermosura ni quiere mujer simpática, tal vez por carecer de gusto estético; le basta con que la mujer sea trabajadora y tenga buena dentadura para mascar la chicha.

A sus hijos nunca reprende ni castiga por nada, siendo entre ellos nula la autoridad paterna. A esto sin duda se debe el que los indios, en cuánto tienen uso de razón aprendan a pelear estropeando a sus padres. Las peleas son muy comunes en las borracheras, pues el indio nunca pelea con nadie sino cuando está embriagado; pero felizmente no tienen ni los mas rudimentarios conocimientos de boxeo, porque de lo contrario, habría muchas muertes. La pelea se reduce a empujarse mutuamente; abrazarse y derribarse en el suelo, arañasos y mordiscotes, siendo la verdadera víctima de toda la ropa con que están vestidos, la que es destrozada sin misericordia quedando muchos en cueros. El alboroto de las peleas es grande, se insultan, se amenazan con la brujería, son rugidos espantosos, remedando a tigres y otras fieras, y, en una palabra, lo que hacen con las manos hacen con la boca. Inútil me parece decir que después de una borrachera 
no que de entre ellos la menor sobra de disgusto y es lo más común ver al siguiente día a dos contendores que la víspera querían matarse, comiendo y riendo juntos en la mejor armonía.

Desaseo.- en cuanto a aseo, todos los indios en general son sucios hasta donde pueden serlo. Si bien se bañan el cuerpo diariamente con agua pura, los trapos con que se cubre mueren vírgenes de haber sido lavados, cuando caen convertidos en harapos de los cuerpos de sus dueños. (Los caucheros han tenido que hacer esfuerzos heroicos para obligar a sus peones a que laven la ropa de vestirse). Cuando la ropa pierde el color natural de la tela y toma el color de la tierra por la mugre, no lavan, sino que tiñen con "sani", (hoja que da un color café obscuro amoratado) tintura con que acaba la ropa en vida de servicio. Como nunca se bañan con jabón, todos los indios exhalan un olor acre, repugnante, al que llaman "chompeto", la mujer que careciera de ese mal olor, carecería de un atractivo, pues yo les he oído, hablando del blanco; uno de los peros que laponen es el no tener "chompeto"y que su cuerpo no huele por tanto a "runa", (indio), sino a jabón.

Indios hembras y varones tienen sus enmarañadas cabeza, que casi nunca se peinan, convertidas en inmensos criaderos de piojos que aumentan intencionalmente como animales domésticos, para en los días de tedio espulgarse y comérselos mutuamente. Las madres, cuando sus hijos no tienen, les ponen intencionalmente en las cabezas, pues el comer piojos, (husa micuna), consideran como una de las más nobles ocupaciones del indio. Muy común es el comer piojos entre marido y mujer, pero lo más general es entre mujeres, período misterioso aquél en que se hacen sus confidencias, se comunican sus secretos y adquieren una intimidad grande. Por eso es que, para designar la confianza mutua que reina entre dos indias dicen "husa micuc pura", (entre comedoras de piojos) es la traducción literal, pero el verdadero sentido es "entre las que nos hemos comido los piojos mutuamente".

Cierta ocasión vi en Archidona a un indio que tenía metidos los pies en un chiquero de chanchos en el que abundan las niguas. - Retírate tonto, - ¿no ves que te llenas de niguas?- y el indio me respondió: -Eso es lo que quiero, porque allá en mi casa no hay y voy a llevar para que aumenten allá-...............después me he convencido de que la nigua, como el piojo, constituyen entretenimiento y alimentación del indio, pues es sacada de la carne, (madura) y comida con avaricia!

Igual cosa hacen con los mosquitos y tábanos que les chupan la sangre: cogerlos llenos y comérselos. Les he preguntado yo porque hacían eso y me han respondido secamente "randi", (desquite), es decir que aplican la ley del talión.

No enumerare aquí otros defectos contra la decencia del aseo y la higiene, por parecerme demasiado repugnantes.

Para comer, en sus casas nunca lo hacen hembras y varones juntos, las mujeres forman un círculo y los hombres otro, en medio de los cuales hay tendidas sobre el suelo hojas de plátanos, y sobre ellas regadas las presas de carne, plátanos cocinados, campeando en la mitad una grande "callana", (cazuela), llena de caldo o mazamorra de plátano y a su lado una mas chica, con ají molido. Cuando ya está servido todo, van tomando asiento en el suelo y principian la comida sin verse entre todos una sola cuchara. Los indios varones son menos sucios que las hembras: van devorando las presas de carnes untadas en ají, y el plátano cocido de la misma manera y van pasándose de unos a otros la cazuela de caldo o mazamorra de la que toman directamente tres ó cuatro bocados, pasándola al vecino, y así sucesivamente; pero las hembras cogen por lo regular el plátano, lo amasan en la mano hasta que se

hace una masa la cual meten con la mano en la cazuela de caldo o mazamorra, dentro de la cual vuelven a amasar hasta que la masa se mezcle con la suficiente humedad del líquido, y desde la cazuela trasladan a la boca, lamiéndose la mano mojada en caldo, hasta el pulso el que en general llevan ceñido por anchas manillas de chaquira o mullos que jamás se quitan 
sino que conservan convertidos en una cinta gruesa de inmundicias a la cual parecen hallarse simétricamente adheridos los mullos............ allí se ven meter muchas manos totalmente cubiertas de lepra; pero ningún indio tiene repugnancia a otro de su especie, porque tienen la creencia de que cuando se tienen el temor y se cuida del contagio éste es seguro; y no es eso verdaderamente sino que las indias, al que le ven receloso de la lepra o asquiento le inoculan inmediatamente por los medios que yo he descrito. A esta creencia se debe sin duda en gran parte la propagación de la lepra casi generalizada en los indios orientales.

El noviazgo.- ninguna india sabe quien deberá ser su marido hasta no ser pedida, pues le hacen casar, quiera o no quiera con el primero que la solicita. El pretendiente nunca pide a una mujer personalmente en matrimonio, sino que designa la mujer de su gusto a los padres o parientes mas cercanos, los que tienen la obligación de "pedir" en matrimonio a la "novia". La pedida es un paso amargo para cualquiera que no sea un indio oriental. Tienen los pedidores que ir adonde los padres de la novia y de rodillas recitar un largo y convincente discurso que dura algo más de 7 horas! Los padres de la novia se hacen rogar demasiado y hay no pocos que tienen que repetir la pedida por 3 o 7 veces, seguidas. Para pedir en matrimonio una india, nunca lo hacen de día sino que esperan a que obscurezca y como no sólo tienen que pedir el consentimiento de los padres sino de todos, hasta los mas lejanos parientes de la novia, hay ocasiones en que demoran hasta ocho y diez noches en esa operación.

Para pedir en matrimonio a una india, nunca lo hacen sin tener una buena cantidad de aguardiente, pues las palabras son alternadas con sendos tragos de aguardiente; y si el o los peticionarios no obtuvieran el consentimiento para el matrimonio, cobran el valor del aguardiente gastado en tal oficio o diligencia. Tan luego luego como obtienen el consentimiento de todos los parientes pactan el matrimonio, "boda" para un día citado. Los padrinos son los que toman sobre si la obligación de "pedir" y, pactado el matrimonio principian los preparativos haciendo enormes ollas de chicha y destilando buenas cantidades de aguardiente.

La boda.- el día citado para la "boda", principia la bebida desde muy por la mañana; se presentan los padrinos a "vestirla", en casa de la novia; la desnudan de la ropa que ha estado puesta y le ponen una falda, le cubren la espalda con dos pañuelos unidos cuyos extremos le sirven para ocultar la cara completamente durante el baile; y le ciñen la cabeza con una cinta roja o azul. La mayor parte de las novias, el momento en que van a vestirlas, por deseosas que estén del matrimonio, huyen, se meten por un yucal o platanal, aparentando una repugnancia que no sienten por tal acto, por que de no hacerlo así, serían el blanco de la crítica mordaz de las demás mujeres. El descrito es todo el ajuar de la novia. Los padrinos se visten de la misma manera que los novios; la madrina sobre todo tiene el mismo vestuario exceptuando sólo la cinta de la cabeza que es una insignia particular de los desposados.

La madrina tienen los mismos pañuelos rojos a la espalda, los que le sirven como alas de una ave para alojar debajo de la derecha a la ruborizada desposada que todo puede sentir menos rubor.

Después de vestida la novia el cortejo se dirige a la casa del novio quien les espera ya vestido con su acostumbrada indumentaria: pantalón y camisa blancos; medias largas, recortados los pies a manera de polainas, sombrero con cinta azul o roja, un poncho blanco de tela fina y sobre el poncho los clásicos pañuelos rojos símbolos de la boda. El padrino vestido tal como el desposado, (a excepción de la cinta) conduce a su ahijado bajo el ala derecha de pañuelo colorado, al baile de ensayo, después de lo cual se dirigen todos a presencia del indio o blanco que hace de cura, quien les hace coger las manos y, después de mil ceremonias les da la bendición y, principia la diversión. Se oye un alboroto infernal, producido por mas de 20 tambores; un canto que no es canto sino un graznido monótono que repite siempre el mismo tono y con pocas variaciones las mismas palabras; un violín que no entona nada y todo esto reunido al agudo y destemplado 
silvido de los "pingullos", (pitos) forman un concierto de romper los oídos a cualquiera, aunque no tenga los menores rudimentos de música....... Luego al baile: se paran en hilera las mujeres en número de 6 ú 8, con la novia y la madrina al centro y paralelamente y en el mismo orden forman otra hilera los varones en número igual. Luego principian el baile con paso lento. Cuando la línea de mujeres avanza, la de varones retrocede, y vice-versa, y de esta manera pasan días y noches, hasta que se completen los tres días de la boda.

No hablaré de la que llaman "chaucha"por no ofender el pudor de los lectores puesto que es una escena salvaje y horrorosamente inmoral que propasa de los límites de la más desvergonzada corrupción, y en esa brutal escena toman parte todos los concurrentes a la "boda".

Pesa sobre el padrino la mal entendida obligación de enseñar sus deberes a la novia, y la madrina hace lo mismo con el novio, de modo que la mujer que se casa, tiene que principiar su carrera por pertenecer al padrino de su matrimonio, a quien se cree mas obligada que al mismo marido, por los gastos de chicha y aguardiente y también por el trabajo de la pedida. Después del padrino viene como segundo en derechos maritales sobre la novia, el suegro, quien ha "criado un hijo varón expresamente para darle marido", y en penúltimo lugar el brujo que ha permitido el matrimonio y les ha consentido que conserven la salud y la vida para casarse. De esta suerte, la mujer india que se casa, se convierte en mujer del padrino; en mujer del suegro, en mujer del brujo, y en último lugar en mujer de su marido, reconociendo todo como sagrados y religiosos preceptos: más claro, el matrimonio es el principio de la poliandria.

Enemigo del blanco.- El indio en general es completamente refractario a la civilización, odian en nosotros hasta el idioma que hablamos al que llaman con naturalidad "supai-shimi", (idioma del demonio). Por convencerles de la superioridad de la raza blanca sobre los indios, por sus costumbres y conocimientos y hacerles perder el horror al idioma español, un vecino de este río, cauchero, patrón de peones, reunió un día a todos los indios y les enseñó un cristo, diciéndoles: "éste es Dios"; luego agregó: - ¿No es verdad que es un "Viraducha”, (blanco) con hermosa barba? - "Todos los indios confesaron que era un viraducho, agregando que era el "amo", (dueño de todo). “- Pues bien, - dijo el patrón: - ustedes dicen y hacen creer a sus hijos que el castellano, idioma que nosotros hablamos, es el idioma del demonio, y es todo lo contrario. Dios es viraducha, habla habla por tanto nuestro idioma. El que muere sin saber hablar el castellano no tiene la menor probabilidad de entrar al cielo, porque aunque tenga derecho de ir allá, Dios no entenderá el quichua; San Pedro, que es el portero, menos aún y colérico que es como viejo, mandará seguramente al infierno a quien vaya a molestarle con cosas que no entiende........ de todos los demás santos no pueden esperar nada, porque todos son viraduchos excepto San Martín que es negro pero habla también el castellano...."con esto parece que se convencieron los indios y, corridos, avergonzados, dejaron de criticar el "supai-shimi", sin poner obstáculos a los que estaban aprendiendo. Si un indio hace padrino de bautismo de su hijo a un blanco, primero le hará bautizar apadrinado por otro indio; luego por otro, y en tercero o cuarto lugar le hace bautizar tomando por padrino al blanco; por si el blanco solo apadrinara el bautismo de una criatura está iría irremediablemente al infierno. Hay indios que hacen bautizar a sus hijos, seis y hasta siete veces, pues esto es además una especulación ya que el padrino tiene la obligación de dar de vestir al ahijado, hasta que este tenga posibilidad de ganarse la vida y también el vestuario.

La envidia es una de las mas principales causas del odio mortal que el indio profesa al blanco. Ven que las costumbres, aún del blanco más corrompido son menos inmorales que las de ellos, ven que son mas fuertes y mas inteligentes y sienten profundo odio, el que se esforzan en transmitirlo y propagarlo con mil cuentos, mentiras y tradiciones a fin de separar su raza de la nuestra e impedir el que aquella se civilice o se mezcle con la nuestra, porque conocen además indiosincracia de las mujeres indias su amor a la comodidad, al lujo y otros caprichos y calculan que si una india se uniera a un blanco y este le diera algunas comodidades, no quisiera retroceder 
a su estado natural de miseria y abyección, y seguido su ejemplo por las demás mujeres, los indios tendrían o que abandonar su pereza para adquirir por el trabajo las mismas comodidades de que disfruta un blanco o desistir a la idea de tener mujeres; y como conocen lo estrechamente limitada que es su inteligencia, se ven totalmente ineptos para la competencia, pero no quieren y deben por su conveniencia confesarse vencidos, sino al contrario; creerse superiores, y, distanciar más los medios posibles a su raza, inculcando a los suyos ese odio dogmático hacia el blanco: labor inútil!..... como si dos arroyos que vienen de un mismo origen y van hacia un mismo mar pudieran correr por el mismo cauce sin mezclarse, por mas que las aguas del uno sean limpias y las del otro turbias!......

He tenido en mi casa sirvientes indias hembras cojidas en tiernas edades y he procurado domesticarles, amoldándoles a nuestras costumbres, he procurado arrancarles sus creencias y enseñarles nuestro idioma. He empleado para ello distintos sistemas entre la dulzura y el rigor y nada he conseguido: han aprendido el idioma por mal y mal cabo, pero dejar sus creencias, habituarse a la nueva vida ni olvidar el odio a nuestra raza, nunca. Criada una desde la edad en 4 años, en 13 años no se ha civilizado. Oculta sus creencias, pero no puede ocultar su apego a los de su raza. Alguien le preguntó un día quien creía ella que sabía más si su patrón o un indio, y ella respondió sin vacilar :- "el indio" y a primera vista parece una mujer racional, habla con perfección el español y se viste como mujer blanca. De esta suerte, el blanco que toma jente india a su servicio creyendo civilizar, inculcar costumbres y más, no consigue sino tener en su casa rabiosos enemigos a quienes mantiene y viste. Yo, por ejemplo, - hombre honrado y padre de una familia legítima fruto del matrimonio, tengo en la servidumbre de mi casa indias de distintas edades a quienes no tolero la prostitución. Ellas criadas en ese ambiente de escandalosa libertad en esas costumbres exageradamente inmorales, en el hetairismo, corrompidas desde que tienen ojos para ver y oídos para oír, extrañan la vida crápula; se sienten arrastradas por sus instintos y por sus pasiones; pero yo les impido todo, porque el consentirles sería corromper a mi familia. Ellos ven pues que yo soy el único obstáculo para que gocen de lo que creen su felicidad y me odian de muerte.

Algunos patroneas creyendo erróneamente a su servidumbre mas contenta, les dan libertas, les permiten asistir a las borracheras y toleran la prostitución, con lo cual, en vez de conseguir remediar agravan la situación, porque el odio, lejos de extinguirse aumenta; ven más pesado el "cautiverio"y quieren conseguir su libertad por cualquier medio, para lo cual van a las borracheras con mentiras, calumnias y más a exasperar los ánimos de los peones y concluyen por rogarles que asesinen a los patrones.

Muchas tentativas de asesinato descubiertas no han tenido otras causas. Y no se creas que ese descontento de las "cholas", (sirvientas indias), sean por malos tratos o cosas parecidas, puesto que aquí, las sirvientas indias tienen consideraciones que en verdad no las merecen ya que nuestros compatriotas moradores de esta región han llegado a creer que el tener una "chola" es una grande suerte, las visten y alimentan de lo mejor y procuran tenerlas lo más contentas: es porque carecen de las absoluta liberta; por que si bien pueden asistir a las borracheras, esto es solo de vez en cuando y no viven en ese ambiente de corrupción entre los indios, en donde tienen libertas día y noche, de andar con quien quieren, hacer lo que quieren y ser mujeres de todos aún sin haberse casado con ninguno.

Creo que todos los patrones de "cholos" habrán observado en las indias esa aversión a la civilización, y habrán quizás tenido algunas mismas contrariedades, y no podrán menos de confesar que tengo completa razón. Los tolerantes, tanto como los intolerantes tienen en su servidumbre un grupo de enemigos que quisieran ver al patrón en medio de una hoguera, tan sólo por sus instintos, que, en casa del "blanco" tienen que reprimirlos algo u ocultarlo siquiera, 
o sujetarlos a reglamentos, mientras que gozando de libertad se entregaran al hetairismo y a la prostitución sin freno. Algunos pobres patrones, aquí consideran como una gran fortuna al tener en sus casas cuatro o mas indias inmorales enfermas con la contagiosa lepra hereditaria de su raza, que sirven de muy mala voluntad y ocasionan casi siempre mas perjuicios que servicios y no consideran que en esas sirvientes tienen los peores enemigos; que tienen en ellas los espías mas minuciosas que observan hasta sus mas mínimos actos; que les desprestigian con calumnias; que son las corruptoras de sus familias y se desviven por vestirles con decencia y hasta lujo, y darles cosas supérfluas sin considerar que los servicios de las indias no recompensan al sacrificio que hace el pobre patrón en inculcarles buenos sentimientos, corregirles sus defectos y, en una palabra, racionalizarles, con peligro de su vida, sacrificio que siempre resulta estéril, pues, atendiendo a la limitadísima inteligencia del indio a su carácter y a sus inclinaciones, querer civilizarlo es como querer poner a flote en la superficie del agua un cuerpo que tenga mayor peso que ella. 